\title{
Evaluation of Risk Factors for Antibiotic Resistance in Patients with Nosocomial Infections Caused by Pseudomonas aeruginosa
}

\author{
Meliha Cagla Sonmezer, ${ }^{1}$ Gunay Ertem, ${ }^{1}$ Fatma Sebnem Erdinc, ${ }^{1}$ Esra Kaya Kilic, \\ Necla Tulek, ${ }^{1}$ Ali Adiloglu, ${ }^{2}$ and Cigdem Hatipoglu ${ }^{1}$ \\ ${ }^{1}$ Department of Clinic of Infectious Diseases and Clinical Microbiology, Ankara Training and Research Hospital, Ankara, Turkey \\ ${ }^{2}$ Department of Microbiology and Clinical Microbiology, Ankara Training and Research Hospital, Ankara, Turkey
}

Correspondence should be addressed to Meliha Cagla Sonmezer; caglasonmezer@hotmail.com

Received 19 April 2016; Revised 3 July 2016; Accepted 25 July 2016

Academic Editor: Jorge Garbino

Copyright (C) 2016 Meliha Cagla Sonmezer et al. This is an open access article distributed under the Creative Commons Attribution License, which permits unrestricted use, distribution, and reproduction in any medium, provided the original work is properly cited.

Background. Pseudomonas aeruginosa (P. aeruginosa) is resistant to various antibiotics and can cause serious nosocomial infections with high morbidity and mortality. In this clinical study, we investigated the risk factors in patients who were diagnosed with $P$. aeruginosa-related nosocomial infection. Methods. A retrospective case control study including patients with $P$. aeruginosa-related nosocomial infection. Patients who were resistant to any of the six antibiotics (imipenem, meropenem, piperacillin-tazobactam, ciprofloxacin, amikacin, and ceftazidime) constituted the study group. Results. One hundred and twenty isolates were isolated. Various risk factors were detected for each antibiotic in the univariate analysis. In the multivariate analysis, previous cefazolin use was found as an independent risk factor for the development of imipenem resistance (OR $=3.33$; CI 95\% [1.11-10.0]; $p=0.03)$, whereas previous cerebrovascular attack $(\mathrm{OR}=3.57$; CI 95\% $[1.31-9.76] ; p=0.01)$ and previous meropenem use $(\mathrm{OR}=4.13$; $\mathrm{CI} 95 \%$ [1.21-14.07]; $p=0.02)$ were independent factors for the development of meropenem resistance. For the development of resistance to ciprofloxacin, hospitalization in the neurology intensive care unit $(\mathrm{OR}=4.24$; CI 95\% $[1.5-11.98] ; p=0.006)$ and mechanical ventilator application $(\mathrm{OR}=11.7 ; \mathrm{CI} 95 \%$ [2.24-61.45]; $p=0.004)$ were independent risk factors. Conclusion. The meticulous application of contact measures can decrease the rate of nosocomial infections.

\section{Introduction}

Healthcare associated infections (HAIs) (or nosocomial infections) are the worldwide public health problem causing morbidity and mortality especially in the developing countries. Furthermore, if the causative organism has developed resistance to a number of antimicrobial agents management of the issue gets harder [1]. The developing countries have taken the commendable strategies of introducing laws to control of HAIs [2].

Intensive care units (ICUs) are units where healthcare infections seen more often because of commonly critically ill patients and invasive interventions used in these units. In ICUs antimicrobial resistance rates are increasing because of various reasons such as broad spectrum and/or inappropriate antimicrobial usage and prolonged length of stay in hospital.
As a result, it increases healthcare infection rates caused by multidrug resistant microorganisms. These infections prolong hospitalization, require more extensive diagnostics and treatment, and are associated with additional costs [3-5].

Device-associated healthcare associated infections (DAHAI) are defined by the Centers for Disease Control and Prevention's (CDC's) National Healthcare Safety Network (NHSN) as infections acquired in a hospital by a patient who was admitted for a reason other than that infection $[6,7]$.

Worldwide view of HAIs in ICUs can be evaluated by comparing studies containing developing and developed several countries [8-10]. According to the KISS data of Germany between 2005 and 2009, P. aeruginosa was causative agent in $17.7 \%$ of ventilator associated pneumonia and $14.2 \%$ of urinary catheter associated urinary tract infections of all ICU infections [8]. According to the INICC data of Iran 
between 2011 and 2012, P. aeruginosa was causative agent in $19 \%$ of ventilator associated pneumonia, $5 \%$ of urinary catheter associated urinary tract infections, $2 \%$ of blood stream infections, and $7 \%$ of surgical site infections of all ICU infections [9].

The infection rates for nosocomial infections and their pathogens differ greatly between different types of ICU corresponding to the different risk structure of the patients. Different studies have been conducted to highlight the incidence and importance of hospital acquired infections in ICUs, to contribute to empirical treatment methods by determining the causes of common hospital infections and antibiotic resistance rates, to minimize the emergence of resistant microorganisms by preventing unnecessary antibiotic use, and to emphasize the need for protective measures against risk factors that favor hospital infections [5-8].

$P$. aeruginosa is an important pathogen, especially in immunocompromised patients. Besides, $P$. aeruginosa causes infections with high morbidity and mortality in intensive care units (ICUs). P. aeruginosa related infections are frequently life threatening and often difficult to treat due to the intrinsic resistance to many antimicrobial agents. Moreover, the resistance to antipseudomonal agents has become an increasing problem in recent years [11-14].

The present study aims to determine the risk factors for the emergence of $P$. aeruginosa infections those are resistant to imipenem, meropenem, piperacillin-tazobactam, amikacin, ceftazidime, or ciprofloxacin and compare the risk factors between isolates that are resistant and sensitive to each antibiotic separately. Furthermore, it aims to guide clinicians regarding treatment and infection control by revealing the relationship between antibiotic resistance and risk factors.

\section{Material and Methods}

2.1. Hospital Settings and Study Population. A retrospective case-control study was conducted at Ankara Training and Research Hospital in Turkey between January 2008 and July 2011. The hospital is a 670-bed referral and tertiary care hospital. The hospital contains medical and surgical ICUs. Neurology, neurosurgery, and anesthesia-reanimation ICUs with 31 total bed capacity were included in the study.

2.2. Study Design and Data Collection. In the hospital, nosocomial infections in ICUs have been determined by prospective, laboratory-based and patient based active surveillance since 2008. In the study, the relevant surveillance data has been evaluated to determine the risk factors for resistant $P$. aeruginosa related infections. Patients who underwent inpatient treatment in these ICUs and were diagnosed as having $P$. aeruginosa related infection 48 hours after being hospitalized were included in the study. The patients with $P$. aeruginosa resistant to selected antibiotics were defined as case groups and the patients with $P$. aeruginosa sensitive to the related antibiotic were defined as control groups.

A list of potential risk factors including the risk factors in the hospital settings was formed consistent with the relevant literature. The risk factors were as follows: gender, age, ICU type, $P$. aeruginosa as a cause of multiple sites of infections, being infected with other resistant microorganisms within 30 days before or concurrently with $P$. aeruginosa infection, existence of comorbid diseases, invasive procedures, antibiotic use, and other drugs within 30 days before the isolation of $P$. aeruginosa.

2.3. Microbiological Examination. All P. aeruginosa were isolated from various clinical specimens in the hospital microbiology laboratory by conventional biochemical methods. Recurrent isolates from the same patient were excluded from the study. The identification and antibiotic susceptibilities of the isolates were made by VITEK II automated system (Biomèrieux, France) and the results were interpreted according to standards of Clinical and Laboratory Standards Institute (CLSI) [15]. Intermediate susceptible isolates were considered to be susceptible.

2.4. Definitions. Nosocomial infections were defined according to the criteria proposed by the Centers for Disease Control and Prevention (CDC) [6]. The patients with nosocomial infection due to resistant (R) strains were compared with those with susceptible (S) strains for the respective antimicrobial resistances, that is, imipenem (IMP-R), meropenem (MEM-R), ceftazidime (CAZ-R), piperacillin-tazobactam (TZP-R), ciprofloxacin (CIP-R), and amikacin (AK-R). The risk factors in nosocomial infections for antimicrobial resistance to imipenem (IMP), meropenem (MEM), piperacillintazobactam (TZP), ceftazidime (CAZ), ciprofloxacin (CIP), and amikacin (AK) were evaluated. After the hospitalization of the patients, antibiotics that were taken 30 days before isolation of $P$. aeruginosa and used for 48 hours and longer were defined as previous antibiotic use. The elapsed time between the admission to ICU and isolation of $P$. aeruginosa was defined as the "risk period."

2.5. Statistical Analysis. The SPSS 15.0 program was used for statistical analysis. The Mann-Whitney $U$ test was used to compare two independent groups. The Chi-square test was used to analyze the categorical variables. In addition, the multiple logistic regression analysis was performed to determine independent risk factors that were influential on being resistant to different antibiotics. Variables included in the model were determined by using univariate statistical methods in the multivariate analysis. Variables with a significance level of $p<0.05$ were compared with multiple logistic regression analysis. Multiple logistic regression analysis results were summarized with odds ratios, $95 \%$ confidence interval, and $p$ values. In the presentation of demographic data as descriptive statistics, rates and frequency were given in qualitative variables, whereas medium (minimum-maximum) and/or mean \pm standard deviation were given in quantitative variables. $p<$ 0.05 was regarded as significant.

\section{Results}

3.1. Demographic and Clinical Features. One hundred twenty isolates that were isolated from 120 patients and met the inclusion criteria were included in the study. Thirty-four $(28.3 \%)$ patients were in neurosurgery ICU, 30 (25\%) patients 
were in Neurology ICU, and $56(46.6 \%)$ patients were in anesthesia-reanimation ICU. During the study, 85 (70.8\%) patients have been died. The hospitalization period was 4413 days in ICU; the period until $P$. aeruginosa isolation was 3-292 days. The distribution of $P$. aeruginosa related infection types was as follows: ventilator associated pneumonia in 61 patients $(50.8 \%)$, urinary system infection in 39 patients $(32.5 \%)$, wound infection in 13 patients $(10.8 \%)$, bloodstream infection in five patients $(4.1 \%)$, and catheter infection in two patients (1.6\%). Among the patients diagnosed with $P$. aeruginosa related infection, 37 (30.8) patients were transferred from another ICU of the hospital and 15 patients $(12.5 \%)$ were transferred from another hospital. One hundred five (87.5\%) patients used an antimicrobial within 30 days before $P$. aeruginosa isolation. The most frequently used antibiotics were carbapenem $(n=73,60.8 \%)$ and meropenem $(n=$ $67,90.1 \%)$. Demographic and clinical characteristics of the study population are described in Table 1 . The majority of the isolates were resistant to imipenem (45.8\%), and then to meropenem and aztreonam (each with 43.3\%). The isolates were mostly sensitive to colistin (100\%), followed by tobramycin $(80 \%)$ and amikacin (78.3\%). Multiple antibiotic resistance was observed in 37 isolates (31.6\%).

3.2. Risk Factors Associated with Antimicrobial Resistance. Various risk factors were detected for each antibiotic between sensitive and resistant $P$. aeruginosa isolates in the univariate analysis. The factors associated with antimicrobial resistance to imipenem, meropenem, and piperacillin-tazobactam are shown in Table 2 and ceftazidime, ciprofloxacin, and amikacin are shown in Table 3. For the patients with IMP-R, MEM-R, TZP-R, CAZ-R, CIP-R, and AK-R P. aeruginosa, the common risk factors were as follows: infection with another microorganism prior to the isolation, an ICU stay $>60$ days, total parenteral nutrition usage as an invasive procedures, comorbid cerebrovascular disease, history of cerebrovascular attack, and antimicrobial use (especially meropenem) within 30 days before the isolation were performed using variables that were significantly associated with the respective antimicrobial resistance in univariate analyses $(p<0.05)$ and the identified independent risk factors are shown in Table 4. According to the analysis, independent risk factors were as follows: for imipenem resistance, previous cefazolin use; for meropenem resistance, history of cerebrovascular attack and previous meropenem use; for amikacin, stay in the ICU > 60 days. The independent risk factor associated with resistance to ciprofloxacin, piperacillin-tazobactam, and ceftazidime was history of stay in NR-ICU in multivariate logistic regression analyses.

\section{Discussion}

The present study is significant as it is a comprehensive study that investigates the risk factors in resistant $P$. aeruginosa infections in ICUs. Previous studies on carbapenem-resistant $P$. aeruginosa (CR- $\mathrm{Pa}$ ) infections have shown that hospitalization in ICU is a major risk factor [16-18]. In the current study, all patients were selected from ICUs. Since the mean ICU stay was $112.7 \pm 87.8$ days, staying in the ICU $>60$ days was
TABLE 1: Demographic and clinical characteristics of patients with $P$. aeruginosa related nosocomial infection.

\begin{tabular}{|c|c|}
\hline Characteristics & $\begin{array}{c}\text { Number of patients } \\
(\%) \\
(n: 120)\end{array}$ \\
\hline Age; years (mean \pm SD) & $58.4 \pm 19.2$ \\
\hline$>60$ years old & $70-58.3$ \\
\hline Male/female & $62-50.8 / 58-49.2$ \\
\hline \multicolumn{2}{|l|}{ Intensive care unit (ICU) } \\
\hline${ }^{\mathrm{a}} \mathrm{NR}-\mathrm{ICU}$ & $34-28.3$ \\
\hline${ }^{\mathrm{b}} \mathrm{AR}-\mathrm{ICU}$ & $56-46.6$ \\
\hline${ }^{\mathrm{c}} \mathrm{NRS}-\mathrm{ICU}$ & $34-28.3$ \\
\hline Stay at ICU $($ mean \pm SD $)$ & $112.7 \pm 87.8$ \\
\hline Intensive care unit stay $>60$ days & $82-68.3$ \\
\hline Polymicrobial infection & $90-75$ \\
\hline Multiple isolation of $P$. aeruginosa & $50-41.7$ \\
\hline Time at risk $($ mean $\pm \mathrm{SD})$ & $55.4 \pm 52.4$ \\
\hline $\begin{array}{l}\text { APACHE II score (mean } \pm \text { SD) (at time of } \\
\text { isolation) }\end{array}$ & $23.6 \pm 4.14$ \\
\hline \multicolumn{2}{|l|}{ Invasive procedures and comorbid disease } \\
\hline Mechanic ventilation & $96-80$ \\
\hline Enteral nutrition & $105-87.5$ \\
\hline Total parenteral nutrition & $87-72.5$ \\
\hline Thoracotomy tube & $17-14.2$ \\
\hline Urinary catheterization & $119-99.2$ \\
\hline Central venous catheterization & $108-90$ \\
\hline History of cerebrovascular disease & $78-65$ \\
\hline History of cardiovascular disease & $98-81.7$ \\
\hline History of surgical operation & $40-33.3$ \\
\hline History of chronic renal disease & $32-26.7$ \\
\hline History of malignancy & $69-57.5$ \\
\hline \multicolumn{2}{|l|}{ Prior antibiotic use } \\
\hline Carbapenems & $73-60.8$ \\
\hline Meropenem & $67-90.1$ \\
\hline Piperacillin-tazobactam & $50-41.7$ \\
\hline Amikacin & $44-36.7$ \\
\hline Teicoplanin & $38-31.7$ \\
\hline Cefazolin & $29-24.2$ \\
\hline Ceftriaxone & $22-18.3$ \\
\hline Ciprofloxacin & $10-8.3$ \\
\hline Ceftazidime & $9-7.5$ \\
\hline
\end{tabular}

${ }^{\mathrm{a}} \mathrm{NR}-\mathrm{ICU}$ : neurology intensive care unit, ${ }^{\mathrm{b}} \mathrm{AR}-\mathrm{ICU}$ : anesthesia-reanimation intensive care unit, and ${ }^{\mathrm{C}} \mathrm{NRS}-\mathrm{ICU}$ : neurosurgery intensive care unit.

evaluated as a risk factor. ICU stay $>60$ days was significantly higher in patients with MEM-RPa or with IMP-RPa when compared to patients with MEM-SPa or IMP-SPa. There was no significant correlation between carbapenem resistance and type of ICU. The univariate analysis showed a significant correlation between multiple isolation of $P$. aeruginosa in the same patient (recurrent infection) as well as polymicrobial infection and imipenem or meropenem resistance. However 
TABLE 2: Univariate analysis of risk factors for antimicrobial resistance in nosocomial infections due to P. aeruginosa (IMP, MEM, and TZP).

\begin{tabular}{|c|c|c|c|c|c|c|c|c|c|}
\hline Risk factors & $\begin{array}{c}{ }^{1} \mathrm{IMP}^{*}{ }^{*} \mathrm{R} \\
(n=56) \\
(n-\%)\end{array}$ & $\begin{array}{c}\text { IMP- }{ }^{* *} \mathrm{~S} \\
(n=64) \\
(n-\%)\end{array}$ & $p$ & $\begin{array}{c}{ }^{2} \text { MEM-R } \\
(n=52) \\
(n-\%) \\
\end{array}$ & $\begin{array}{c}\text { MEM-S } \\
(n=68) \\
(n-\%)\end{array}$ & $p$ & $\begin{array}{c}{ }^{3} \mathrm{TZP}-\mathrm{R} \\
(n=44) \\
(n-\%) \\
\end{array}$ & $\begin{array}{c}\text { TZP-S } \\
(n=76) \\
(n-\%) \\
\end{array}$ & $p$ \\
\hline$>60$ years old & $31-55.4$ & $39-60.9$ & 0.536 & $27-51.9$ & $43-63.2$ & 0.213 & $26-59.1$ & $44-57.9$ & 0.898 \\
\hline Sex (male) & $28-50$ & $33-51.6$ & 0.864 & $24-46.2$ & $35-51.5$ & 0.564 & $20-45.5$ & $41-53.9$ & 0.370 \\
\hline \multicolumn{10}{|l|}{$\begin{array}{l}\text { Intensive care unit } \\
\text { type }\end{array}$} \\
\hline${ }^{\mathrm{a}} \mathrm{NR}-\mathrm{ICU}$ & $14-25$ & $16-25$ & \multirow{3}{*}{0.782} & $16-30.8$ & $14-20.6$ & \multirow{3}{*}{0.206} & $20-45.5$ & $10-13.2$ & \multirow{3}{*}{$<0.001$} \\
\hline${ }^{\mathrm{b}} \mathrm{AR}-\mathrm{ICU}$ & $25-44.6$ & $32-50$ & & $20-38.5$ & $37-54.4$ & & $17-38.6$ & $40-52.6$ & \\
\hline${ }^{\mathrm{c}} \mathrm{NRS}-\mathrm{ICU}$ & $17-30.4$ & $16-25$ & & $16-30.8$ & $17-25$ & & $7-15.9$ & $26-34.2$ & \\
\hline $\begin{array}{l}\text { Intensive care unit } \\
\text { stay }>60 \text { days }\end{array}$ & $47-83.9$ & $35-54.7$ & 0.001 & $46-88.5$ & $36-52.9$ & $<0.001$ & $34-77.3$ & $48-63.2$ & 0.109 \\
\hline $\begin{array}{l}\text { Polymicrobial } \\
\text { infection }\end{array}$ & $49-87.5$ & $41-64.1$ & 0.003 & $46-88.5$ & $44-64.7$ & 0.003 & $38-86.4$ & $52-68.4$ & 0.029 \\
\hline $\begin{array}{l}\text { Multiple isolation of } \\
P . \text { aeruginosa }\end{array}$ & $34-60.7$ & $16-25$ & $<0.001$ & $32-61.5$ & $18-26.5$ & $<0.001$ & $19-43.2$ & $31-40.8$ & 0.798 \\
\hline Time at risk $>30$ days & $43-76.8$ & $36-56.2$ & 0.018 & $40-76.9$ & $39-57.4$ & 0.024 & $32-72.7$ & $47-61.8$ & 0.226 \\
\hline $\begin{array}{l}\text { APACHE II score } \\
(\text { mean } \pm \text { SD) } \\
\text { (at time of isolation) }\end{array}$ & $24.1 \pm 5.8$ & $23.1 \pm 6.6$ & 0.435 & $24 \pm 5.6$ & $22.2 \pm 4.6$ & 0.739 & $24.6 \pm 6.3$ & $23 \pm 6.1$ & 0.164 \\
\hline Mechanic ventilation & $48-85.7$ & $48-75$ & 0.143 & $44-84.6$ & $42-72.5$ & 0.269 & $38-86.4$ & $58-76.3$ & 0.185 \\
\hline Enteral nutrition & $53-94.6$ & $52-81.3$ & 0.027 & $48-92.3$ & $57-83.8$ & 0.164 & $40-90.9$ & $65-85.5$ & 0.390 \\
\hline $\begin{array}{l}\text { Total parenteral } \\
\text { nutrition }\end{array}$ & $47-83.9$ & $40-62.5$ & 0.009 & $43-82.7$ & $44-64.7$ & 0.029 & $38-86.4$ & $49-64.5$ & 0.010 \\
\hline Thoracotomy tube & $9-16.1$ & $8-12.5$ & 0.576 & $7-13.5$ & $10-14.7$ & 0.846 & $7-15.9$ & $10-13.2$ & 0.677 \\
\hline $\begin{array}{l}\text { History of } \\
\text { cerebrovascular } \\
\text { disease }\end{array}$ & $40-71.4$ & $38-59.4$ & 0.167 & $42-80.8$ & $36-52.9$ & 0.002 & $30-68.2$ & $48-63.2$ & 0.578 \\
\hline $\begin{array}{l}\text { History of } \\
\text { cardiovascular disease }\end{array}$ & $49-87.5$ & $49-76.6$ & 0.122 & $47-90.4$ & $51-75$ & 0.031 & $39-88.6$ & $59-77.6$ & 0.133 \\
\hline $\begin{array}{l}\text { History of surgical } \\
\text { operation }\end{array}$ & $21-37.5$ & $19-29.7$ & 0.365 & $18-34.6$ & $22-32.4$ & 0.794 & $9-20.5$ & $31-40.8$ & 0.023 \\
\hline $\begin{array}{l}\text { Prior receipt of } \\
\text { cefazolin }\end{array}$ & 19-33.9 & $10-15.6$ & 0.019 & $14-26.9$ & $15-22.1$ & 0.537 & $7-15.9$ & $22-28.9$ & 0.108 \\
\hline $\begin{array}{l}\text { Prior receipt of } \\
\text { ceftazidime }\end{array}$ & $8-14.3$ & $1-1.6$ & 0.008 & $7-13.5$ & $2-2.9$ & 0.030 & $2-4.5$ & $7-9.2$ & 0.350 \\
\hline $\begin{array}{l}\text { Prior receipt of } \\
\text { meropenem }\end{array}$ & $42-75$ & $25-39.1$ & $<0.001$ & $42-80.8$ & $25-36.8$ & $<0.001$ & $31-70.5$ & $36-47.4$ & 0.014 \\
\hline $\begin{array}{l}\text { Prior receipt of } \\
\text { amikacin }\end{array}$ & $28-50$ & $16-25$ & 0.005 & $26-50$ & $18-26.5$ & 0.008 & $18-40.9$ & $26-34.2$ & 0.463 \\
\hline $\begin{array}{l}\text { Prior receipt of } \\
\text { piperacillin- } \\
\text { tazobactam }\end{array}$ & $26-46.4$ & $24-37.5$ & 0.322 & $25-48.1$ & $25-36.8$ & 0.213 & $24-54.5$ & $26-34.2$ & 0.029 \\
\hline $\begin{array}{l}\text { Prior receipt of } \\
\text { ciprofloxacin }\end{array}$ & $4-7.1$ & $6-9.4$ & 0.659 & $7-13.5$ & $3-4.4$ & 0.076 & $7-15.9$ & $3-3.9$ & 0.022 \\
\hline $\begin{array}{l}\text { Prior receipt of } \\
\text { teicoplanin }\end{array}$ & $25-44.6$ & $13-20.3$ & 0.004 & $20-38.5$ & $18-26.5$ & 0.162 & $16-36.4$ & $18-23.7$ & 0.137 \\
\hline
\end{tabular}

${ }^{\mathrm{a}} \mathrm{NR}-\mathrm{ICU}$ : neurology intensive care unit, ${ }^{\mathrm{b}} \mathrm{AR}-\mathrm{ICU}$ : anesthesia-reanimation intensive care unit, and ${ }^{\mathrm{c}} \mathrm{NRS}$-ICU: neurosurgery intensive care unit.

${ }^{1}$ IMP: imipenem, ${ }^{2}$ MEM: meropenem, and ${ }^{3}$ TZP: piperacillin-tazobactam.

${ }^{*} \mathrm{R}$ : resistant and ${ }^{* *} \mathrm{~S}$ : sensitive.

in multivariate analyses these variables were not detected as independent risk factors. Studies on carbapenem-resistant $\mathrm{Pa}$ infections have not frequently focused on these two risk factors. The means of time at risk (until the isolation of $P$. aeruginosa) were higher in both the imipenem and meropenem-resistant group. Longer risk periods increase the ratios of infection with resistant microorganisms. The high rate of infection history with another microorganism further 
TABLE 3: Univariate analysis of risk factors for antimicrobial resistance in nosocomial infections due to P. aeruginosa (CIP, AK, and CAZ).

\begin{tabular}{|c|c|c|c|c|c|c|c|c|c|}
\hline Risk factors & $\begin{array}{c}{ }^{1} \mathrm{CIP}-{ }^{*} \mathrm{R} \\
(n=40) \\
(n-\%)\end{array}$ & $\begin{array}{c}\mathrm{CIP}^{* *} \mathrm{~S} \\
(n=80) \\
(n-\%)\end{array}$ & $p$ & $\begin{array}{c}{ }^{2} \mathrm{AK}-\mathrm{R} \\
(n=26) \\
(n-\%)\end{array}$ & $\begin{array}{c}\text { AK-S } \\
(n=94) \\
(n-\%)\end{array}$ & $p$ & $\begin{array}{c}{ }^{3} \mathrm{CAZ}-\mathrm{R} \\
(n=38) \\
(n-\%)\end{array}$ & $\begin{array}{c}\text { CAZ-S } \\
(n=82) \\
(n-\%)\end{array}$ & $p$ \\
\hline$>60$ years old & $22-55$ & $48-60$ & 0.600 & $14-53.8$ & $56-59.6$ & 0.600 & $25-65.8$ & $45-54.9$ & 0.259 \\
\hline Sex (male) & $21-52.5$ & $40-50$ & 0.796 & $13-50$ & $48-51.1$ & 0.923 & $17-44.7$ & $44-53.7$ & 0.363 \\
\hline \multicolumn{10}{|l|}{$\begin{array}{l}\text { Intensive care unit } \\
\text { type }\end{array}$} \\
\hline NR-ICU ${ }^{\mathrm{a}}$ & $15-37.5$ & $15-18.8$ & \multirow{3}{*}{0.025} & $9-34.6$ & $21-22.3$ & \multirow{3}{*}{0.356} & $19-50$ & $11-13.4$ & \multirow{3}{*}{$<0.001$} \\
\hline AR-ICU ${ }^{b}$ & $18-45$ & $39-48.8$ & & $12-46.2$ & $45-47.9$ & & $14-36.8$ & $43-52.4$ & \\
\hline NRS-ICU ${ }^{c}$ & $7-17.5$ & $26-32.5$ & & $5-19.2$ & $28-29.8$ & & $5-13.2$ & $28-34.1$ & \\
\hline $\begin{array}{l}\text { Intensive care unit } \\
\text { stay }>60 \text { days }\end{array}$ & $31-77.5$ & $51-63.6$ & 0.127 & $24-92.3$ & $58-61.7$ & 0.003 & $28-73.7$ & $54-65.9$ & 0.391 \\
\hline $\begin{array}{l}\text { Polymicrobial } \\
\text { infection }\end{array}$ & $35-87.5$ & $55-68.8$ & 0.025 & $23-88.5$ & $67-71.3$ & 0.073 & $33-86.8$ & $57-69.5$ & 0.041 \\
\hline $\begin{array}{l}\text { Multiple isolation of } \\
\text { P. aeruginosa }\end{array}$ & $19-47.5$ & $31-38.8$ & 0.359 & $12-46.2$ & $38-40.4$ & 0.600 & $18-47.4$ & $32-39$ & 0.388 \\
\hline Time at risk $>30$ days & $20-76.9$ & $58-61.7$ & 0.150 & $21-80.8$ & $58-61.7$ & 0.070 & $26-68.4$ & $53-64.6$ & 0.684 \\
\hline $\begin{array}{l}\text { APACHE II score } \\
(\text { mean } \pm \text { SD) } \\
\text { (at time of isolation) }\end{array}$ & $24.9 \pm 6.9$ & $22.9 \pm 5.8$ & 0.104 & $24.3 \pm 6.9$ & $23.4 \pm 6.1$ & 0.523 & $25.3 \pm 6.4$ & $22.8 \pm 6.0$ & 0.039 \\
\hline Mechanic ventilation & $38-95$ & $58-72.5$ & 0.004 & $23-88.5$ & $73-77.3$ & 0.223 & $30-78.9$ & $66-80.5$ & 0.844 \\
\hline Enteral nutrition & $38-95$ & $67-83.8$ & 0.079 & $25-96.2$ & $80-85.1$ & 0.132 & $34-89.5$ & $71-86.6$ & 0.656 \\
\hline $\begin{array}{l}\text { Total parenteral } \\
\text { nutrition }\end{array}$ & $32-80$ & $55-68.8$ & 0.193 & $22-84.6$ & $65-6.1$ & 0.118 & $31-81.6$ & $56-86.3$ & 0.129 \\
\hline Thoracotomy tube & $7-17.5$ & $10-12.5$ & 0.459 & $7-26.9$ & $10-10.6$ & 0.035 & $4-10.5$ & $13-15.9$ & 0.436 \\
\hline $\begin{array}{l}\text { History of } \\
\text { cerebrovascular } \\
\text { disease }\end{array}$ & $28-70$ & $50-62.5$ & 0.417 & $17-65.4$ & $61-64.9$ & 0.963 & $28-73.7$ & $50-61$ & 0.175 \\
\hline $\begin{array}{l}\text { History of } \\
\text { cardiovascular disease }\end{array}$ & $35-87.5$ & $63-78.8$ & 0.243 & $22-84.6$ & $76-80.9$ & 0.661 & $35-92.1$ & $63-76.8$ & 0.044 \\
\hline $\begin{array}{l}\text { History of surgical } \\
\text { operation }\end{array}$ & $10-25$ & $30-37.5$ & 0.171 & $4-15.4$ & $36-38.3$ & 0.028 & $5-13.2$ & $35-42.7$ & 0.001 \\
\hline $\begin{array}{l}\text { Prior receipt of } \\
\text { cefazolin }\end{array}$ & $8-20$ & $21-26.3$ & 0.451 & $5-19.2$ & $24-25.5$ & 0.507 & $5-13.2$ & $24-29.3$ & 0.055 \\
\hline $\begin{array}{l}\text { Prior receipt of } \\
\text { ceftazidime }\end{array}$ & $1-2.5$ & $8-10$ & 0.141 & $1-3.8$ & $8-8.5$ & 0.424 & $2-5.3$ & $7-8.5$ & 0.527 \\
\hline $\begin{array}{l}\text { Prior receipt of } \\
\text { meropenem }\end{array}$ & $28-70$ & $39-48.8$ & 0.027 & $20-76.9$ & $47-50$ & 0.014 & $26-68.4$ & $41-50$ & 0.059 \\
\hline $\begin{array}{l}\text { Prior receipt of } \\
\text { amikacin }\end{array}$ & $16-40$ & $28-35$ & 0.592 & $12-46.2$ & $32-34$ & 0.257 & $16-42.1$ & $28-34.1$ & 0.400 \\
\hline $\begin{array}{l}\text { Prior receipt of } \\
\text { piperacillin- } \\
\text { tazobactam }\end{array}$ & $20-50$ & $30-37.5$ & 0.190 & $13-50$ & $37-39.4$ & 0.330 & $20-52.6$ & $30-36.6$ & 0.091 \\
\hline $\begin{array}{l}\text { Prior receipt of } \\
\text { ciprofloxacin }\end{array}$ & $6-15$ & $4-5$ & 0.062 & $3-11.5$ & $7-7.4$ & 0.504 & $6-15.8$ & $4-4.9$ & 0.044 \\
\hline $\begin{array}{l}\text { Prior receipt of } \\
\text { teicoplanin }\end{array}$ & $14-35$ & $24-30$ & 0.579 & $9-34.6$ & $29-30.9$ & 0.715 & $12-31.6$ & $26-31.7$ & 0.989 \\
\hline
\end{tabular}

${ }^{\mathrm{a}}$ NR-ICU: neurology intensive care unit, ${ }^{\mathrm{b}}$ AR-ICU: anesthesia-reanimation intensive care unit, and ${ }^{\mathrm{c}}$ NRS-ICU: neurosurgery intensive care unit.

${ }^{1} \mathrm{CIP}$ : ciprofloxacin, ${ }^{2} \mathrm{AK}$ : amikacin, and ${ }^{3} \mathrm{CAZ}$ : ceftazidime.

${ }^{*} \mathrm{R}$ : resistant and ${ }^{* *} \mathrm{~S}$ : sensitive.

supports this possibility. Prolonged exposure to antibiotics in recurrent infections and the use of broad spectrum antibiotics in polymicrobial infections were considered to lead the selection of resistant microorganisms. Similar studies have shown that the mean risk period is significantly high in the imipenem-resistant group $[18,19]$.

When we evaluated the correlation between underlying diseases and resistance development, we did not identify 
TABLE 4: Independent risk factors associated with the perspective antimicrobial resistances in resistant to antipseudomonal antibiotics related to nosocomial $P$. aeruginosa infections.

\begin{tabular}{lcc}
\hline Variables & $\begin{array}{c}\text { Adjusted OR } \\
(95 \% \mathrm{CI})\end{array}$ & $p$ \\
\hline $\begin{array}{l}\text { Resistance to imipenem } \\
\quad \text { Prior receipt of cefazolin }\end{array}$ & $3.33(1.11-10.0)$ & 0.03 \\
$\begin{array}{l}\text { Resistance to meropenem } \\
\text { History of cerebrovascular disease }\end{array}$ & $3.57(1.31-9.76)$ & 0.01 \\
$\quad \begin{array}{c}\text { Prior receipt of meropenem } \\
\text { Resistance to piperacillin-tazobactam }\end{array}$ & 0.02 \\
$\quad$ Stay at neurology intensive care unit & $(1.21-14.07)$ & \\
Resistance to ciprofloxacin & 4.47 & \\
Stay at neurology intensive care unit & $4.24(1.5-11.94)$ & 0.003 \\
Mechanic ventilation & 11.7 & 0.006 \\
Resistance to amikacin & $(2.24-61.45)$ & 0.004 \\
Intensive care unit stay > 60 days & $(1.60-33.02)$ & 0.01 \\
Thoracotomy tube & 3.41 & 0.04 \\
Resistance to ceftazidime & $(1.03-11.24)$ & \\
Stay at neurology intensive care unit & $(1.92-13.34)$ & 0.001 \\
\hline
\end{tabular}

any significant comorbid diseases in imipenem-resistant infections. However, the rate of cardiovascular diseases and history of SVO were significantly higher in the meropenemresistant group. History of SVO was identified as an independent risk factor for meropenem-resistant $P$. aeruginosa infections. We believe that the incidence of meropenemresistant strains increased, since imipenem is not preferred due to its potential convulsive effect in patients with a central nervous system (CNS) disease. However, further studies are required to support this correlation. When we examined the invasive procedures, TPN and NG catheterization were significantly higher in the imipenem-resistant group, and TPN was significantly higher in the meropenem-resistant group. However, it was not identified as an independent risk factor in the multivariate analysis. To the best of our knowledge, there have been no studies that have identified TPN and NG as independent risk factors for meropenemor imipenem-resistant $P$. aeruginosa infections. On the other hand, some studies have linked hemodialysis, tracheostomy, arterial way, SVK, and MV to meropenem or imipenem resistance [16-18, 20, 21].

In the evaluation of previous antibiotic use, the use of cefazolin, ceftazidime, meropenem, and amikacin within 30 days before isolation was higher in the imipenemresistant group. On the other hand, the multivariate analysis showed that only cefazolin use was an independent risk factor. Univariate analysis in the meropenem-resistant group showed higher usage rates of ceftazidime, meropenem, and amikacin; however, the multivariate analysis showed that only meropenem use was an independent risk factor. Previous studies have identified previous imipenem use as an independent risk factor for IMP-RPa infection [16, 18, 21]. According to a study by Juan et al., the effects of primary resistance rates in ICU and endemic clones are low, whereas secondary resistance rates (resistance development during treatment) are high [22]. This condition highlights the importance of antibiotic use and its efficacy in resistance development. Cefazolin was preferred more frequently for surgical prophylaxis in surgical ICUs, compared to nonsurgical ICUs, and the differences in total patient numbers (87 patients in AR-ICU and NRS-ICU and 30 patients in the NR-ICU) are thought to be responsible for this outcome. Additionally, MEM is preferred more frequently than IMP in NR-ICU. Similar studies on hospital infections that are seen in general hospital populations have not identified first-generation cephalosporin use as a risk factor for carbapenem resistance $[18,19]$. Furtado et al. analyzed the risk factors in pneumonia cases with IMP-RPa and identified third-generation cephalosporin use as an independent risk factor [17]. Similar studies have also identified piperacillin-tazobactam use as an independent risk factor for the development of imipenem resistance, and this finding was attributed to the selection of strains with suppressed beta-lactamase production [16, $17,19]$. In the current study, ceftazidime and piperacillintazobactam use were significantly higher in both imipenemresistant and meropenem-resistant groups, but these factors were not identified as independent risk factors.

The incidence of piperacillin-tazobactam resistant $P$. aeruginosa (TZP-RPa) infections has increased as a result of ineffective inhibition of chromosomal beta lactamases by tazobactam; however, the incidence is lower compared to carbapenem-resistant infections [23]. In the United States, between 1998 and 2004, TZP-RPa was identified as a cause of infection in ICUs (17.5\%), non-ICU facilities (11.6\%), and patients who receive medical care outside hospitals (6\%) [24]. TZP-RPa strains are responsible for $40 \%$ of all causes of hospital infections in Turkey [25]. Similar to the previous studies in Turkey, we found that 44 of 120 P. aeruginosa strains (36.7\%) strains were resistant to piperacillin-tazobactam. Different studies on resistant $P$. aeruginosa infections have shown that ICU stay is a major risk factor [26-28]. In the present study we classified our patients with respect to the type of ICU. We determined that staying in the NR-ICU as an independent risk factor for (TZP-RPa) infections. The mean age of patients in NR-ICU was $67.9 \pm 14.3$ years and was higher compared to the other ICUs. The mean APACHE II scores (at the time of $P$. aeruginosa isolation) and the mean risk period (63.3 \pm 49.1 days) were higher compared to other ICUs; however, the mean stay in NR-ICU patients ( $96.8 \pm 61.8$ days) was shorter. CVD as the primary diagnosis of majority of the patients and the higher incidence of $>2$ comorbid diseases support the finding that NR-ICU stay is an independent risk factor. Among the invasive interventions, TPN application had higher frequency. The use of TZP, MEM, and CIP within 30 days before isolation was significantly higher in the TZP-RPa group. To date, studies have identified previous use of piperacillin-tazobactam, imipenem, aminoglycosides, vancomycin, and third-generation cephalosporins as 
independent risk factors $[27,28]$. Similar studies of hospital infections in the same settings have identified the use of broad spectrum cephalosporins, ciprofloxacin, and fluoroquinolones within 30 days before isolation as an independent risk factor $[26,29,30]$.

Studies on fluoroquinolone-resistant $P$. aeruginosa (FQ$\mathrm{RPa}$ ) infections have shown that ICU stay is an important risk factor $[26,31,32]$. In the current study, we identified NR-ICU stay as an independent risk factor for the development of CIP-RPa infections. According to the Medline database, there are no studies that investigate these risk factors in fluoroquinolone-resistant $P$. aeruginosa infections $[32,33]$. In the present study, the univariate analysis showed a significant correlation between polymicrobial infections with other microorganisms at the time of $P$. aeruginosa isolation and CIP-RPa. Two studies have shown that polymicrobial bacteremia is not a risk factor for antipseudomonal FQ- $\mathrm{RPa}$ related bacteremia [26, 29]. Among the invasive interventions, mechanic ventilation was identified as an independent risk factor. Two studies have identified urinary catheterization and invasive procedures within 72 hours before bacteremia development as independent risk factors for the development of CIP-RPa bacteremia [26, 29]. In another study, tracheostomy and chemotherapy have been identified as independent risk factors for the development of ciprofloxacin- and imipenem-resistant infections [32]. In this study, prior use of MEM within 30 days before isolation was identified as a risk factor. Ciprofloxacin use was higher in the resistant group, but this finding was not statistically significant. Similar studies have identified previous use of fluoroquinolones as an independent risk factor for the development of CIP-RPa infections [29-31, 34]. Lee et al. found that previous levofloxacin use is an independent risk factor for $P$. aeruginosa hospital infections, but they did not determine a significant correlation between previous ciprofloxacin use [35]. On the other hand, two different studies identified a significant correlation between previous carbapenem and fluoroquinolone use and resistance development $[26,36]$. In the current study, ciprofloxacin use was higher in the resistant group, but this finding was not statistically significant.

According to the Medline database, there are only a limited number of epidemiological studies on aminoglycoside resistance of $P$. aeruginosa. In the current study, the univariate analysis of risk factors that favored $\mathrm{AK}-\mathrm{RPa}$ infections showed that ICU stay $>60$ days, thoracotomy tube, and prior meropenem use were significantly higher in the resistant group. Among these risk factors, we identified the thoracotomy tube as an independent risk factor. To the best of our knowledge, there are no previous studies that investigated the application of a thoracotomy tube as a potential risk factor. According to a study on risk factors in AK-RPa related bacteremia, the use of fluoroquinolones within 90 days before isolation, urinary catheterization, and percutaneous catheterization are independent risk factors [29]. Another study indicated that risk factors that lead to gentamicin resistance in $P$. aeruginosa, previous gentamicin use, and multiple antibiotic use are independent risk factors [37]. Another study indicated that previous use of meropenem and amikacin is independent risk factors for AK-RPa [37]. Previous use of first and third-generation cephalosporins and piperacillin is independent risk factors for CAZ-RPa infections in a similar study [35]. Fortaleza et al. found that previous amikacin use is an independent risk factor for the development of CAZ-RPa infections [18]. In the current study NR-ICU stay was the only independent risk factor for the development of CAZ-RPa. The underlying causes of NR-ICU stay being an independent risk factor were mentioned in the section of TZP-RPa. The same causes are also independent risk factors for the development of CAZ-RPa. In addition, we found a significant correlation between polymicrobial infections before isolation of $P$. aeruginosa and the development of $\mathrm{CAZ}-\mathrm{R} P \mathrm{P}$. In a similar study, polymicrobial infection is not a risk factor for the development of CAZ-RPa; however, it is an independent risk factor for mortality [29]. Comorbid cardiovascular diseases and decubitus ulcer were significant for the development of CAZ-RPa infections. Cardiovascular diseases (92.1\%) were the most common comorbid disease in the resistant group. Two studies on risk factors that affect the development of resistance to antipseudomonal antibiotics in $P$. aeruginosa related bacteremia have identified solid tumors as the most common underlying disease; however, this was not identified as a risk factor $[26,29]$. Some of the previous studies have demonstrated that urinary catheterization, percutaneous catheterization, and invasive intervention within 72 hours before isolation are independent risk factors [34] on the contrary of this study. We determined that invasive procedures and medical interventions were not risk factors for the development of ceftazidime resistance. Some of the previous studies have demonstrated that urinary catheterization, percutaneous catheterization, and invasive intervention within 72 hours before isolation are independent risk factors [29]. The frequency of surgical operations in the ceftazidimesensitive group was significantly higher compared to the ceftazidime-resistant group.

The effective treatment of infections caused by $P$. aeruginosa includes prevention when possible and source control measures as necessary and prompt administration of appropriate antimicrobial agents. If antimicrobial susceptibilities are known, deescalation should be pursued in patients especially with an appropriate clinical response. Hand hygiene and barrier precautions are important to keep the spread of infection in ICUs. Therefore surveillance is important in providing useful information for physicians in choosing empirical antibiotics [38-40].

\section{Conclusion}

To date, most of the studies including the present study have indicated the fact that long-term hospitalization of patients with poor overall condition with multiple invasive procedures and intense antibiotic pressure (especially carbapenemclass antibiotics) have led to resistant $P$. aeruginosa infections.

These results should be taken into consideration to comprehend the importance of limiting antibiotic use in order to prevent resistance to antibiotics that can be used for the treatment of life threatening infections. 


\section{Competing Interests}

The authors declare that they have no competing interests.

\section{Authors' Contributions}

Meliha Cagla Sonmezer and Necla Tulek conceived, designed, and did statistical analysis and editing of manuscript. Esra Kaya Kilic, Fatma Sebnem Erdinc, Ali Adiloglu, Cigdem Hatipoglu, and Gunay Ertem did data collection and manuscript writing. Gunay Ertem and Fatma Sebnem Erdinc did review and final approval of manuscript.

\section{References}

[1] J. Xu, X. Duan, H. Wu, and Q. Zhou, "Surveillance and correlation of antimicrobial usage and resistance of Pseudomonas aeruginosa: a hospital population-based study," PLoS ONE, vol. 8, no. 11, Article ID e78604, 2013.

[2] M. Biswal, A. Mewara, S. B. Appannanavar, and N. Taneja, "Mandatory public reporting of healthcare-associated infections in developed countries: how can developing countries follow?" Journal of Hospital Infection, vol. 90, no. 1, pp. 12-14, 2015.

[3] J.-L. Vincent, D. J. Bihari, P. M. Suter et al., “The prevalence of nosocomial infection in intensive care units in Europe: results of the European Prevalence of Infection in Intensive Care (EPIC) study," The Journal of the American Medical Association, vol. 274, no. 8, pp. 639-644, 1995.

[4] A. I. Hidron, J. R. Edwards, J. Patel et al., "Antimicrobialresistant pathogens associated with healthcare-associated infections: annual summary of data reported to the National Healthcare Safety Network at the Centers for Disease Control and Prevention, 2006-2007," Infection Control and Hospital Epidemiology, vol. 29, no. 11, pp. 996-1011, 2008.

[5] D. Pittet and S. J. Harbarth, "The intensive care unit," in Hospital Infections, J. V. Bennett and P. S. Brachman, Eds., pp. 338-402, Lippincott-Raven, Philadelphia, pa, USA, 4th edition, 1998.

[6] T. C. Horan, M. Andrus, and M. A. Dudeck, "CDC/NHSN surveillance definition of health care-associated infection and criteria for specific types of infections in the acute care setting," American Journal of Infection Control, vol. 36, no. 5, pp. 309-332, 2008.

[7] M. A. Dudeck, L. M. Weiner, K. Allen-Bridson et al., "National Healthcare Safety Network (NHSN) report, data summary for 2012, device-associated module," American Journal of Infection Control, vol. 41, no. 12, pp. 1148-1166, 2012.

[8] C. H. R. Geffers and P. Gastmeier, "Nosocomial infections and multidrug-resistant organisms in Germany: epidemiological data from KISS (the Hospital Infection Surveillance System)," Deutsches Ärzteblatt International, vol. 108, no. 6, pp. 87-93, 2011.

[9] S. Jahani-Sherafat, M. Razaghi, V. D. Rosenthal et al., "Deviceassociated infection rates and bacterial resistance in six academic teaching hospitals of Iran: findings from the International Nocosomial Infection Control Consortium (INICC)," Journal of Infection and Public Health, vol. 8, no. 6, pp. 553-561, 2015.

[10] M. A. Dudeck, J. R. Edwards, K. Allen-Bridson et al., "National healthcare safety network report, data summary for 2013, device-associated module," American Journal of Infection Control, vol. 43, no. 3, pp. 206-221, 2015.
[11] J. A. Driscoll, S. L. Brody, and M. H. Kollef, “The epidemiology, pathogenesis and treatment of Pseudomonas aeruginosa infections," Drugs, vol. 67, no. 3, pp. 351-368, 2007.

[12] D. E. Craven and A. Chroneou, "Nosocomial pneumonia," in Principles and Practice of Infectious Diseases, G. L. Mandell, J. E. Bennett, and R. Dolin, Eds., vol. 2, pp. 3717-3724, Elsevier, Philadelphia, Pa, USA, 7th edition, 2010.

[13] R. Gaynes, J. R. Edwards, and National Nosocomial Infections Surveillance System, "Overview of nosocomial infections caused by gram-negative bacilli," Clinical Infectious Diseases, vol. 41, no. 6, pp. 848-854, 2005.

[14] T. G. Emori, D. H. Culver, T. C. Horan et al., "National nosocomial infections surveillance system (NNIS): description of surveillance methods," American Journal of Infection Control, vol. 19, no. 1, pp. 19-35, 1991.

[15] National Committee for Clinical Laboratory Standards, "Methods for the dilution antimicrobial susceptibility tests for bacteria that grow aerobically," Approved Standard M100-S20, National Committee for Clinical Laboratory Standards, 2010.

[16] P. Onguru, A. Erbay, H. Bodur et al., "Imipenem-resistant Pseudomonas aeruginosa: risk factors for nosocomial infections," Journal of Korean Medical Science, vol. 23, no. 6, pp. 982-987, 2008.

[17] G. H. C. Furtado, M. D. Bergamasco, F. G. Menezes et al., "Imipenem-resistant Pseudomonas aeruginosa infection at a medical-surgical intensive care unit: risk factors and mortality," Journal of Critical Care, vol. 24, no. 4, pp. 625.e9-625.e14, 2009.

[18] C. M. C. B. Fortaleza, M. P. Freire, D. C. M. Filho, and M. C. Ramos, "Risk factors for recovery of imipenem- or ceftazidime-resistant Pseudomonas aeruginosa among patients admitted to a teaching hospital in Brazil," Infection Control and Hospital Epidemiology, vol. 27, no. 9, pp. 901-906, 2006.

[19] A. D. Harris, D. Smith, J. A. Johnson, D. D. Bradham, and M.-C. Roghmann, "Risk factors for imipenem-resistant Pseudomonas aeruginosa among hospitalized patients," Clinical Infectious Diseases, vol. 34, no. 3, pp. 340-345, 2002.

[20] K. J. Eagye, J. L. Kuti, and D. P. Nicolau, "Risk factors and outcomes associated with isolation of meropenem high-levelresistant Pseudomonas aeruginosa," Infection Control and Hospital Epidemiology, vol. 30, no. 8, pp. 746-752, 2009.

[21] A. P. Zavascki, R. P. Cruz, and L. Z. Goldani, "Risk factors for imipenem-resistant Pseudomonas aeruginosa: a comparative analysis of two case-control studies in hospitalized patients," Journal of Hospital Infection, vol. 59, no. 2, pp. 96-101, 2005.

[22] C. Juan, O. Gutierrez, A. Oliver, J. I. Ayestarán, N. Borrell, and J. L. Pérez, "Contribution of clonal dissemination and selection of mutants during therapy to Pseudomonas aeruginosa antimicrobial resistance in an intensive care unit setting," Clinical Microbiology and Infection, vol. 11, no. 11, pp. 887-892, 2005.

[23] Z. Djordjevic, O. Gajovic, Z. Mijailovic, A. Ilic, and R. Stolic, "Risk factors of nosocomial infections caused by piperacillintazobactam resistant Pseudomonas aeruginosa," Srpski Arhiv za Celokupno Lekarstvo, vol. 141, no. 9-10, pp. 640-647, 2013.

[24] National Nosocomial Infections Surveillance (NNIS), "System Report, data summary from January 1992 through June 2004, issued October 2004," American Journal of Infection Control, vol. 32, no. 8, pp. 470-485, 2004.

[25] S. Gençer, Ö. Ak, N. Benzonana, A. Batirel, and S. Özer, "Susceptibility patterns and cross resistances of antibiotics against Pseudomonas aeruginosa in a teaching hospital of Turkey," 
Annals of Clinical Microbiology and Antimicrobials, vol. 1, article 2, 2002.

[26] C.-I. Kang, S.-H. Kim, W. B. Park et al., "Risk factors for antimicrobial resistance and influence of resistance on mortality in patients with bloodstream infection caused by Pseudomonas aeruginosa," Microbial Drug Resistance, vol. 11, no. 1, pp. 68-74, 2005.

[27] A. D. Harris, E. Perencevich, M.-C. Roghmann, G. Morris, K. S. Kaye, and J. A. Johnson, "Risk factors for piperacillintazobactam-resistant Pseudomonas aeruginosa among hospitalized patients," Antimicrobial Agents and Chemotherapy, vol. 46, no. 3, pp. 854-858, 2002.

[28] N. Patel, L.-A. McNutt, and T. P. Lodise, "Relationship between various definitions of prior antibiotic exposure and piperacillintazobactam resistance among patients with respiratory tract infections caused by Pseudomonas aeruginosa," Antimicrobial Agents and Chemotherapy, vol. 52, no. 8, pp. 2933-2936, 2008.

[29] E.-J. Joo, C.-I. Kang, Y. E. Ha et al., "Risk factors for mortality in patients with Pseudomonas aeruginosa bacteremia: clinical impact of antimicrobial resistance on outcome," Microbial Drug Resistance, vol. 17, no. 2, pp. 305-312, 2011.

[30] M. López-Dupla, J.-A. Martínez, F. Vidal et al., "Previous ciprofloxacin exposure is associated with resistance to $\beta$-lactam antibiotics in subsequent Pseudomonas aeruginosa bacteremic isolates," American Journal of Infection Control, vol. 37, no. 9, pp. 753-758, 2009.

[31] L. B. Gasink, N. O. Fishman, M. G. Weiner, I. Nachamkin, W. B. Bilker, and E. Lautenbach, "Fluoroquinolone-resistant Pseudomonas aeruginosa: assessment of risk factors and clinical impact," The American Journal of Medicine, vol. 119, no. 6, pp. 526.e19-526.e25, 2006.

[32] M. R. Mueller, M. K. Hayden, S. K. Fridkin et al., "Nosocomial acquisition of Pseudomonas aeruginosa resistant to both ciprofloxacin and imipenem: a risk factor and laboratory analysis," European Journal of Clinical Microbiology and Infectious Diseases, vol. 27, no. 7, pp. 565-570, 2008.

[33] D. I. Hsu, M. P. Okamoto, R. Murthy, and A. Wong-Beringer, "Fluoroquinolone-resistant Pseudomonas aeruginosa: risk factors for acquisition and impact on outcomes," Journal of Antimicrobial Chemotherapy, vol. 55, no. 4, pp. 535-541, 2005.

[34] L. B. Gasink, T. E. Zaoutis, W. B. Bilker, and E. Lautenbach, "The categorization of prior antibiotic use: impact on the identification of risk factors for drug resistance in case control studies," American Journal of Infection Control, vol. 35, no. 10, pp. 638-642, 2007.

[35] S. C. Lee, C. P. Fung, P. Y. Liu et al., "Nosocomial infections with ceftazidime-resitant Pseudomonas aeruginosa: risk factors and outcome," Infection Control \& Hospital Epidemiology, vol. 20, no. 3, pp. 205-207, 1999.

[36] A. Vitkauskiene, E. Skrodeniene, A. Dambrauskiene, A. Macas, and R. Sakalauskas, "Pseudomonas aeruginosa bacteremia: resistance to antibiotics, risk factors, and patient mortality," Medicina, vol. 46, no. 7, pp. 490-495, 2010.

[37] F. L. Ruben, C. W. Norden, and F. Hruska, "Factors associated with acquisition of Pseudomonas aeruginosa resistant to gentamicin," American Journal of the Medical Sciences, vol. 275, no. 2, pp. 173-179, 1978.

[38] S. Esen and H. Leblebicioglu, "Prevalence of nosocomial infections at intensive care units in Turkey: a multicentre 1-day point prevalence study," Scandinavian Journal of Infectious Diseases, vol. 36, no. 2, pp. 144-148, 2004.
[39] L. Raka, "Lowbury Lecture 2008: infection control and limited resources-searching for the best solutions," The Journal of Hospital Infection, vol. 72, no. 4, pp. 292-298, 2009.

[40] E. Alp, H. Leblebicioglu, M. Doganay, and A. Voss, "Infection control practice in countries with limited resources," Annals of Clinical Microbiology and Antimicrobials, vol. 10, article 36, 2011. 


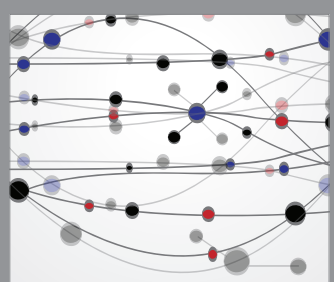

The Scientific World Journal
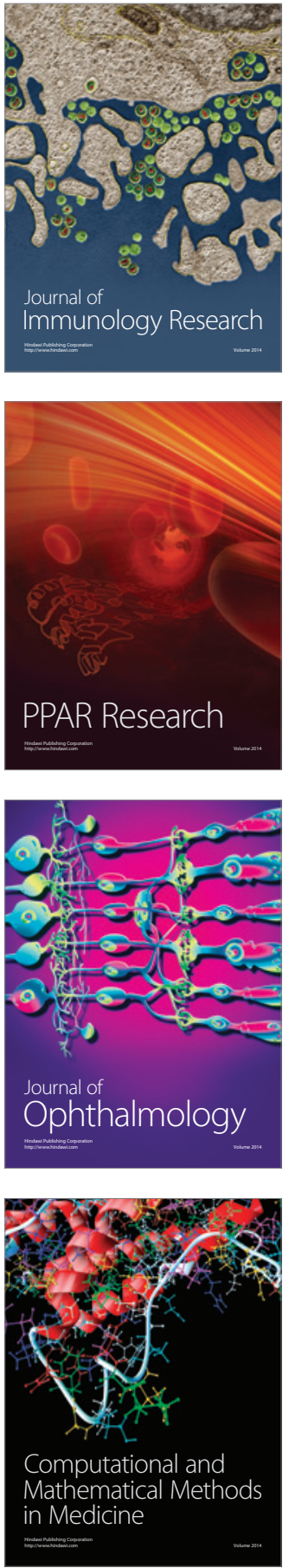

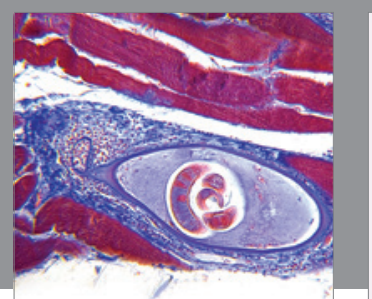

Gastroenterology Research and Practice

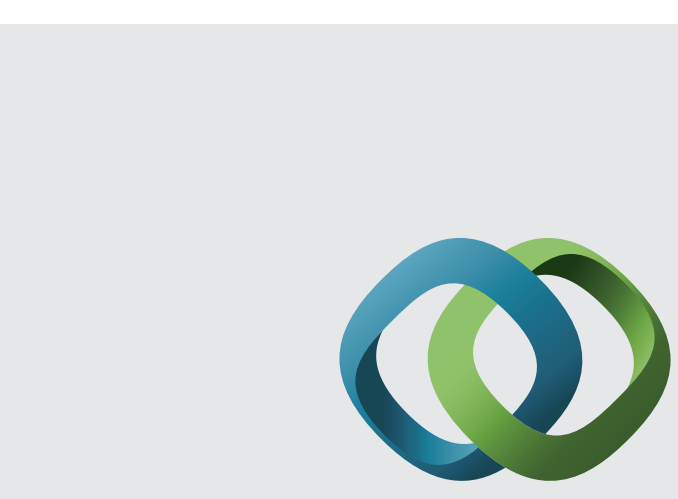

\section{Hindawi}

Submit your manuscripts at

http://www.hindawi.com
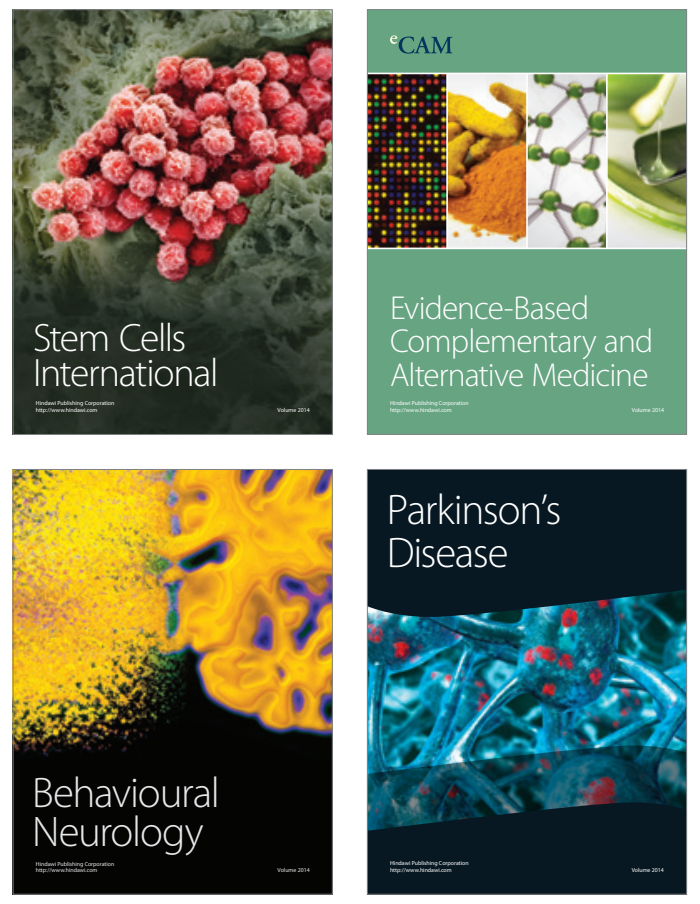
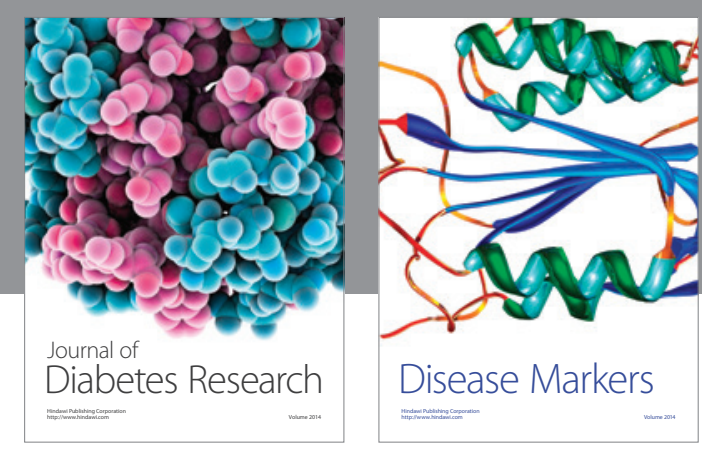

Disease Markers
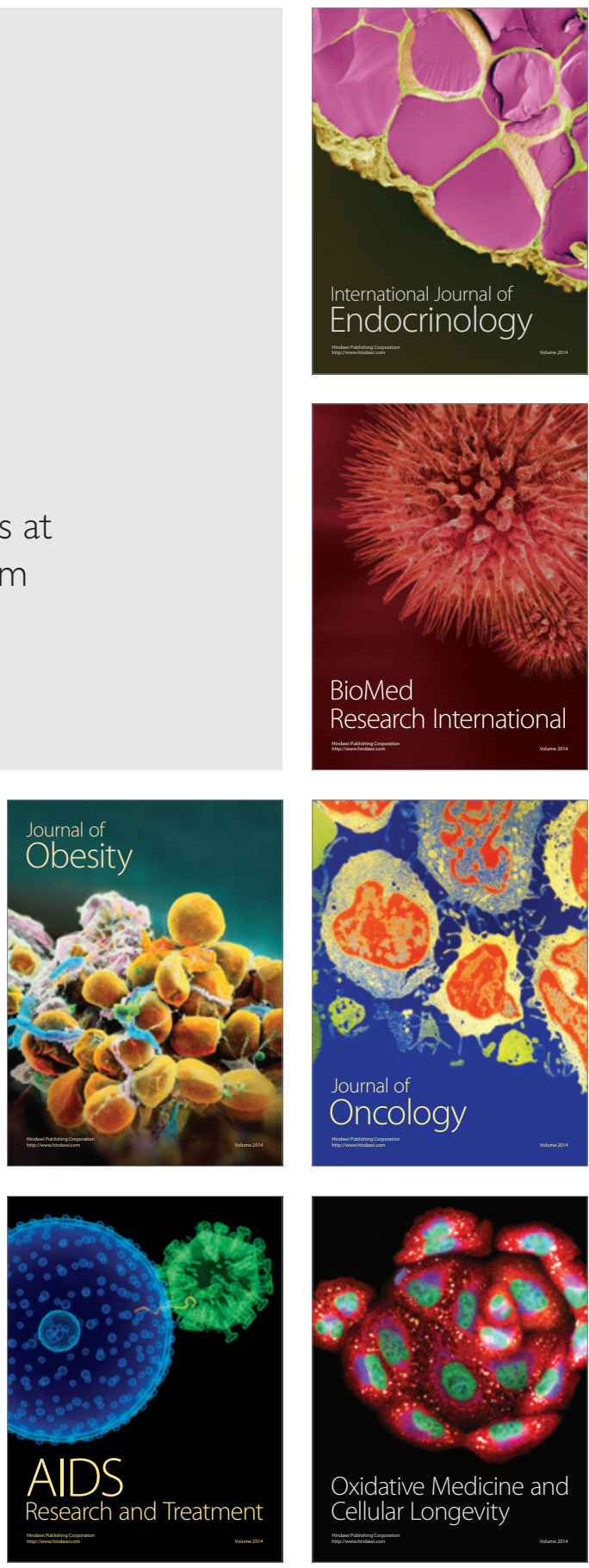